\title{
Effects of conjugated linoleic acids fed to dairy cows during early gestation on hematological, immunological, and metabolic characteristics of cows and their calves
}

\author{
S. Dänicke, ${ }^{\star 1}$ J. Kowalczyk, ${ }^{\star}$ L. Renner, ${ }^{\star}$ J. Pappritz, ${ }^{\star}$ U. Meyer, ${ }^{\star}$ R. Kramer,† E.-M. Weber,‡ S. Döll, ${ }^{*}$ \\ J. Rehage,‡ and G. Jahreis† \\ *Institute of Animal Nutrition, Friedrich-Loeffler-Institute (FLI), Federal Research Institute for Animal Health, D-38116 Braunschweig, Germany \\ †Institute of Nutrition, Friedrich Schiller University Jena, D-07743 Jena, Germany \\ ¥University of Veterinary Medicine Hannover, Clinic for Cattle, D-30173 Hannover, Germany
}

\begin{abstract}
The aim of the present experiment was to test the stimulation ability of peripheral blood mononuclear cells (PBMC) expressed as stimulation index (SI) of newborn calves and of their dams fed a control fat supplement $(\mathrm{CON}, \mathrm{n}=6)$ or 50 and $100 \mathrm{~g} / \mathrm{d}$ of a CLA-containing fat supplement (CLA50, $\mathrm{n}=5$, and CLA100, $\mathrm{n}=6$, respectively) during the preceding lactation period for $182 \mathrm{~d}$ after calving. The total intake of cis-9,trans-11 and trans-10,cis-12 CLA by groups CLA50 and CLA100 amounted to 4 and $8 \mathrm{~g} / \mathrm{d}$ each, respectively. For this purpose, blood was collected immediately after parturition from calves before and after colostrum intake, and from cows after parturition and $21 \mathrm{~d}$ later. The SI was related to the fatty acid composition of erythrocyte and milk lipids and to various hematological and clinical-chemical parameters. Retrospective evaluation revealed that depletion time (i.e., the individual period elapsed between the day of terminating the feeding of the experimental diet in the preceding lactation period and the day of calving) ranged from 190 to $262 \mathrm{~d}$, which corresponded to fetal exposure times of 19 to $102 \mathrm{~d}$. The SI from cows increased significantly by 77 and $55 \%$, within $21 \mathrm{~d}$ after calving according to the 3-[4,5-dimethylthiazol-2-yl]-2,5-diphenyl-tetrazolium bromide (MTT) and Alamar Blue assays, respectively. However, feeding of $50 \mathrm{~g}$ of the CLA product failed to demonstrate this increase in the MTT assay. Moreover, SI was significantly lower for calves whose dams belonged to the CLA50 group, whereas stimulation ability was comparable for the PBMC from calves whose mothers were treated with CON and CLA100. Plasma metabolites (total bilirubin, total cholesterol, glucose, nonesterified fatty acids, 3 - $\beta$-hydroxybutyrate, total protein, and albumin) and hematological parameters (hematocrit,
\end{abstract}

Received August 28, 2011.

Accepted February 5, 2012.

${ }^{1}$ Corresponding author: Sven.Daenicke@fli.bund.de white blood cell profile) were not significantly influenced by dietary treatments of the cows in the preceding lactation period. Although the fatty acid pattern of erythrocyte lipids of cows remained uninfluenced, that of calves showed alterations due to the feeding type of their dams. For example, C16:0 increased significantly from 14.4 to $16.9 \%$ of total fatty acid methyl esters, whereas cis-9,trans-11 CLA increased slightly from 0.11 to $0.15 \%$ at the same time in calves when their mothers were fed the CLA100 instead of the CON diet. Fatty acid profile of colostrum was significantly different from that of milk after 3 wk for most of the detected fatty acids, but was not influenced by diet type. In conclusion, feeding a CLA-containing fat supplement during the preceding lactation and gestation period exerted effects on the stimulation ability of PBMC from cows and calves for the subsequent parturition. However, CLA dose effects were inconsistent and require further investigation.

Key words: conjugated linoleic acids, cow, calf, peripheral blood mononuclear cells

\section{INTRODUCTION}

Conjugated linoleic acids (CLA) comprise a group of positional and geometric isomers of octadecadienoic acid (linoleic acid, C18:2) characterized by conjugated double bonds (e.g., Bauman et al., 1999). The conjugation of the double bond results in conformational properties different from the unconjugated linoleic acid forms. These changes might have a marked effect on the biological activities of CLA, depending on the position of the double bonds within the $\mathrm{C} 18$ backbone and on the cis and trans conformation. Generally, 2 isomers are of special importance: cis-9,trans-11 CLA and trans10,cis-12 CLA. Although the former naturally occurs at higher concentrations in cattle milk and tissues, the latter has been associated with a milk fat-depressing effect (Bauman and Griinari, 2001; Mir et al., 2004). The reasons for using rumen-protected CLA feed 
supplements in dairy cow feeding are not only the milk fat-depressing and milk yield-enhancing properties of CLA, but also their potential to counteract the negative energy balance of the early lactating cow (Selberg et al., 2004).

However, considering that absorbed CLA not only influences milk fat synthesis but might also be incorporated into phospholipids of membranes of many body cells, it seems conceivable that their function might be influenced as well. Bovine peripheral blood mononuclear cells (PBMC) were shown to be influenced by increasing free fatty acid concentrations in the culture medium (Lacetera et al., 2004), and human T lymphocyte mitogen-induced activation was dose-dependently decreased specifically by increasing proportions of both cis-9,trans-11 CLA and trans-10,cis-12 CLA in cell lipids ex vivo (Tricon et al., 2004).

Given the fact that the nutrition of the dam affects nutrition and metabolism of the developing fetus, it is of interest whether an intrauterine exposure to specific nutrients such as CLA, which might have long-term consequences on the immune system via incorporation into membranes of cells with longer half-lives, might also have long-term consequences for the immune system of the newborn calf.

Thus, the aim of the present experiment was to test the functionality of PBMC of newborn calves before and after colostrum intake and of their dams fed a control fat supplement $(\mathbf{C O N})$ or 50 and 100 $\mathrm{g} / \mathrm{d}$ of a CLA-containing fat supplement (CLA50 and CLA100, respectively) during the preceding lactation period, immediately after parturition, and $21 \mathrm{~d}$ later. These data were then related to the FA composition of erythrocytes as a long-term marker for CLA exposure (Jaudszus et al., 2010) and to various hematological and clinical-chemical parameters.

\section{MATERIALS AND METHODS}

\section{Experimental Design and Feeding}

Preceding Lactation Period (CLA Feeding Period). Pregnant cows that were used for the present investigations originated from a long-term feeding experiment in which graded levels of CLA were fed to cows beginning after calving. The experiment and the procedures are described elsewhere in detail (Pappritz et al., 2011a). Briefly, 46 pregnant German Holstein cows were assigned to 1 of the 3 dietary treatments (CON, CLA50, or CLA100) according to the mean BW (627 $\pm 9 \mathrm{~kg}$, cows only), mean number of lactations (1.9 \pm 0.1 ), and milk yield of previous lactation (5,797 \pm $122 \mathrm{~kg}, 200-\mathrm{d}$ milk yield). Fat supplements were fed for
$182 \mathrm{~d}$ via $4 \mathrm{~kg}$ of concentrates supplied by a self-feeding concentrate station (Insentec B.V., Marknesse, the Netherlands), whereas the daily ration was completed by ad libitum offering of a partial mixed ration (PMR) consisting of $37 \%$ concentrate, and $63 \%$ silage $(60 \%$ maize and $40 \%$ grass silage on a DM basis). Concentrates contained $38.5 \%$ wheat, $9.0 \%$ dried sugar beet pulp, $20.0 \%$ rapeseed meal, $6.5 \%$ soybean meal, $1.0 \%$ soybean oil, $0.5 \%$ calcium carbonate, $2.0 \%$ mineral feed $(140 \mathrm{~g}$ of $\mathrm{Ca}, 120 \mathrm{~g}$ of $\mathrm{Na}, 70 \mathrm{~g}$ of P, $40 \mathrm{~g}$ of Mg, $6 \mathrm{~g}$ of $\mathrm{Zn}, 5.4 \mathrm{~g}$ of $\mathrm{Mn}, 1 \mathrm{~g}$ of $\mathrm{Cu}, 100 \mathrm{mg}$ of I, $40 \mathrm{mg}$ of Se, $5 \mathrm{mg}$ of Co, 1,000,000 IU of vitamin A, 100,000 IU of vitamin $\mathrm{D}_{3}, 1,500 \mathrm{mg}$ of vitamin $\mathrm{E}$ per $\mathrm{kg}$ of mineral feed), and $2.5 \%$ of a CLA supplement or $2.5 \%$ of a control fat supplement. A rumen-protected fat preparation (Silafat, BASF SE, Ludwigshafen, Germany) and commercial CLA preparation (Lutrell Pure, BASF SE) were used as CON and CLA supplements, respectively.

The composition of the concentrate portion of the PMR was similar to the described concentrate but contained no fat supplement. During the depletion period, the cows received only the PMR, without extra concentrate, for a period of $84 \mathrm{~d}$. After a total of $266 \mathrm{~d}$, the feeding experiment with the intensive individual data recording was terminated. The PMR was fed until the beginning of the dry period.

The dry period ration was formulated as a TMR and consisted of $80 \%$ roughage $(60 \%$ and $40 \%$ maize and grass silage, respectively) and $20 \%$ concentrate, consisting of $31 \%$ wheat, $31 \%$ barley, $11.5 \%$ dried sugar beet pulp, $20.0 \%$ soybean meal, $6.5 \%$ mineral feed $(50 \mathrm{~g}$ of $\mathrm{Ca}, 70 \mathrm{~g}$ of $\mathrm{P}, 120 \mathrm{~g}$ of $\mathrm{Na}, 60 \mathrm{~g}$ of $\mathrm{Mg}, 800,000 \mathrm{IU}$ of vitamin A, 100,000 IE of vitamin $\mathrm{D}_{3}, 2,500 \mathrm{mg}$ of vitamin, 4,000 $\mathrm{mg}$ of $\mathrm{Mn}, 6,000 \mathrm{mg}$ of $\mathrm{Zn}, 1,250 \mathrm{mg}$ of $\mathrm{Cu}, 100 \mathrm{mg}$ of I, $35 \mathrm{mg}$ of $\mathrm{Co}$, and $50 \mathrm{mg}$ of Se per $\mathrm{kg}$ of mineral feed).

All diets were formulated to meet the nutritional requirements of the cows as stated by the German Society of Nutrition Physiology (GfE, 2001).

Following Lactation Period (Cow and Calf Observation Period). After calving the cows were offered a mixture of $60 \%$ maize and $40 \%$ grass silage (DM basis) for ad libitum consumption, whereas the concentrate portion was steadily increased during the first $14 \mathrm{~d}$ postpartum from 1.5 to $8 \mathrm{~kg}$ of DM. The upper amount of concentrate was maintained from wk 3 of lactation. Mineral and vitamin supply corresponded to that described for the preceding lactation period.

The calves stayed with their dams for approximately $1 \mathrm{~d}$ (16 to $24 \mathrm{~h}$ ) postpartum. Therefore, the calves had unlimited access to the colostrum of their corresponding dams. Thereafter, they were kept in small stables $(87 \times 175 \mathrm{~cm})$ on straw and fed $6 \mathrm{~L}$ of pooled colostrum 
per day in 2 equal portions in the morning and afternoon for $7 \mathrm{~d}$. After this colostrum period, the calves were transferred to group boxes with straw bedding for another $42 \mathrm{~d}$. They were fed a commercial milk replacer (skim milk powder $41.9 \%$, whey powder $35.9 \%$, and vegetable oil, refined and homogenized $13.4 \%$ ) during this period using automatic self-feeders.

Data Recording and Sample Collection (Cow and Calf Observation Period). As one aim of the present observation period was to investigate blood parameters of unsuckled calves, only those dams and their offspring were sampled where parturition was under the personal control of the staff (i.e., during the daytime). Because of this precondition, only 5 to 6 corresponding dams and calves were used out of 15 to 16 potentially available pregnant cows per group. Sampled cows ranged from second to sixth lactation. In particular, 6 $(\mathrm{n}=2, \mathrm{n}=3$ and $\mathrm{n}=1$ in the second, third, and fifth lactation), $5(\mathrm{n}=3, \mathrm{n}=1$, and $\mathrm{n}=1$ in the second, third, and fifth lactation), and $6(\mathrm{n}=3$ and $\mathrm{n}=3$ in the second and third lactation) cows of the groups CON, CLA50, and CLA100 were used for the present investigations. Blood was drawn from one external jugular vein both of the dam and of the calf immediately after expulsion. A second blood sample was collected from calves after they spent 16 to $24 \mathrm{~h}$ with their dams in the morning (approximately $0700 \mathrm{~h}$ ) before separating from each other. Thus, calves had ad libitum access to colostrum within this period. Consequently, the amount of consumed colostrum between both blood samples could not be recorded. A second blood sample from cows was collected after 3 wk in lactation. Calves were weighed upon separation from cows before entering the calf stable. Each cow was equipped with an ear transponder enabling the individual recording of the daily intake of the PMR and of the concentrates, as well as of the milk yield and BW. The first BW of cows after calving was recorded when the cows left the calving unit after separation from their calves. Samples for determination of milk composition were collected twice a week in the morning and in the afternoon of the same day. The milk samples were preserved using bronopol and stored at $8^{\circ} \mathrm{C}$ until they were analyzed. In addition, $100-\mathrm{mL}$ samples of colostrum (immediately postpartum) and milk 3 wk after calving were taken for the analysis of the FA profile of milk fat. The samples were stored at $-20^{\circ} \mathrm{C}$ and subsequently freeze-dried. Calf weight was recorded after birth, and at d 8 and 50 of age.

The experiment and the procedures were in accordance with the European Community regulations concerning the protection of experimental animals and the guidelines of the LAVES (Lower Saxony State Office for Consumer Protection and Food Safety, Germany, File Number 33.14.42502-04-071/07).

\section{Sample Preparation and Analysis}

Hematology and functionality tests of PBMC were performed for all 3 treatment groups, whereas FA profile of erythrocyte lipids and milk fat was determined for groups CON and CLA100 only, to investigate the general effects of CLA on FA transfer and metabolism. Heparin plasma and serum samples were prepared by centrifugation from the corresponding blood samples and stored at $-80^{\circ} \mathrm{C}$ along with the erythrocytecontaining blood cake for further analysis. Total leucocytes were counted using an improved Neubauer Cell Counting Chamber. Hematocrit was determined after centrifugation using a hematocrit centrifuge. Differential leukocyte counts were evaluated after panoptic staining of the smear according to Pappenheim (Kraft and Dürr, 2005) and counting 200 cells.

Peripheral blood mononuclear cells were separated by gradient centrifugation using Ficoll separation solution from heparinized blood diluted with PBS at a ratio of $1: 1$ for ex vivo examination of viability and proliferation as described in detail elsewhere (Dänicke et al., 2011; Renner et al., 2011). Viability and Concanavalin A (ConA)-stimulated cell proliferation were analyzed by the 3-[4,5-dimethylthiazol-2-yl]-2,5-diphenyl-tetrazolium bromide (MTT) and the Alamar Blue (AB) assays, as described previously (Renner et al., 2011).

Milk samples were analyzed for fat, protein, lactose, and SCC using an infrared milk analyzer (Milkoscan FT 6000 combined with a Fossomatic 500, Foss Electric, Hillerød, Denmark). The milk samples for determination of FA profile were heated to $40^{\circ} \mathrm{C}$ and homogenized using an Ultra Turrax (T25, Janke \& Kunkel, IKA-Labortechnik, Staufen, Germany). The so-treated samples of the morning and evening milkings were mixed based on the corresponding milk yields and subsequently freeze-dried. Fat was extracted according to Soxhlet method as described by VDLUFA (Naumann and Bassler, 1993). Total milk fat was converted into its fatty acid methyl esters (FAME) using sodium methoxide as a catalyst.

Lipids of the feed and fat supplements were extracted by the Folch method (Folch et al., 1956) and thereafter transesterified using boron trifluoride $\left(\mathrm{BF}_{3}\right)$ for conversion into FAME. Erythrocyte lipids were extracted from homogenized samples using a methanol:chloroform mixture as described in detail previously (Bligh and Dyer, 1959; Jaudszus et al., 2010). All extracts were purified by thin-layer chromatography (SIL G-25 UV $\mathrm{UV}_{254}$, Macherey-Nagel, Düren, Germany).

All sample FAME extracts were analyzed using a gas chromatograph (GC-17A Version 3, Shimadzu, Tokyo, Japan) equipped with an auto sampler and a flameionization detector. Two different GC methods were 
necessary to analyze the detailed FAME profile of the samples. First, the identity and general profile of FA with a length of between 4 to 25 carbon atoms was determined using a medium polarity column (DB-225ms, $60 \mathrm{~m}$ long $\times 0.25 \mathrm{~mm}$ i.d., $0.25 \mu \mathrm{m}$; J\&W Scientific, Köln, Germany). With the second GC method, the cis and trans isomers of C18:1 were separated using a high-polarity column (Select FAME, $200 \mathrm{~m}$ long $\times 0.25$ mm i.d., $0.25 \mu \mathrm{m}$; Varian Inc., Waldbronn, Germany). Various reference standards were used as FAME mix to identify FA peaks: No. 463, 674, (Nu-Chek Prep Inc., Elysian, MN); BR2, BR4, ME 93 (Larodan, Malmö, Sweden); and Supelco 37 Component FAME Mix, PUFA No. 3, conjugated linoleic acid, linoleic-, linolenic-, and octadecenoic acid methyl ester mix (Supelco, Bellefonte, PA). The results were expressed as percentage values of total FAME.

Clinical-chemical parameters were analyzed by the laboratory of the Cattle Clinic Hanover (Germany). Briefly, plasma NEFA and glucose levels were determined by enzymatic procedures using commercial kits (NEFA HR(2) R1+R2 Set, Wako Chemicals GmbH, Neuss, Germany; Hexokinase Fluid 5+1, MTI Diagnostics GmbH, Idstein, Germany). Plasma concentrations of 3- $\beta$-hydroxybutyrate (BHBA) were quantified using a commercial kit (Ranbut, RB 1008; Randox Laboratories $\mathrm{GmbH}$, Wülfrath, Germany). Protein and albumin contents were determined by using the Biuret method and the bromocresol green method, respectively. Total bilirubin and cholesterol were analyzed by photometric tests. All clinical-chemical procedures were performed using the Cobas Mira Plus Chemistry Analyzer (F. Hoffmann-La Roche Ltd., Basel, Switzerland).

\section{Calculations}

Depletion time was the single period elapsed between the day of feed termination in the experimental diet in the preceding lactation period and the day of calving. The proportions of FA in milk fat and erythrocyte lipids that were below the detection limits were considered zero in evaluating the data.

The results of the ex vivo examinations of the PBMC were expressed as stimulation index (SI), which was defined as the ratio between the optical density in the MTT assay and the fluorescence in the AB assay of ConA-stimulated PBMC and nonstimulated PBMC.

\section{Statistics}

All results are presented as least squares means and standard errors (SE). All statistics were performed by using SAS software (version 9.1, SAS Institute Inc., Cary, NC). Generally, the MIXED procedure was used to evaluate the data. For all parameters, depletion time was introduced into the respective model as a covariable to account for the individual span between the termination of the CLA feeding and calving. Moreover, dietary treatment in the preceding lactation period (CON, CLA50, CLA100) was principally considered as a fixed effect. In evaluating the hematological parameters, the plasma metabolites, the functionality of the PBMC, and the FA composition of the erythrocyte lipids and of milk fat. The day of measurement (cows: d $0=$ day of birth and d 21 in milk; calves: d 0, day of birth = before colostrum, and d 1 of life $=$ after colostrum) was the second fixed effect. The interactions between diet and day of measurement were additionally considered as fixed effects. The repeated statement was used to account for the repeated measurement of each cow or calf within treatments.

In evaluating milk and calf performance, the model was reduced to the diet effect as fixed factor and the depletion time as the co-variable. Analysis of BW of calves at birth included the sex of the calves and the interaction between diet and sex as fixed factors. Body weight at birth served as an additional co-variable in evaluating the BW gain of the calves. The latter covariable was also considered in evaluating the gestation length.

Among the covariance structures tested for the models, the compound symmetry (CS) was found to be the most appropriate according to the Akaike information criterion. Effects were considered significant at $P \leq$ 0.05 , whereas a tendency or trend was assumed for probabilities $<0.1$ and $>0.05$.

Besides the complex evaluation of the effects of the diet, the depletion time, and the day of measurement on various parameters, comparison of the FA profiles of erythrocytes of cows and their calves as measured exclusively after birth was of interest to characterize feto-maternal relationships independently of colostrum intake by the calves. For this purpose, the corresponding mean value differences between pairs of cows and calves within the group were tested for significance using a $t$-test for paired variables.

\section{RESULTS}

\section{CLA Composition of Fat Supplements and Exposure of Cows}

The CON and CLA supplements contained 10.89 and 10.89\% C16:0, 87.30 and 50.31\% C18:0, <0.01 and $10.66 \% \mathrm{C} 18: 1$ cis-9, 0.06 and $11.99 \% \mathrm{C} 18: 2$ cis9,trans- 11 , and 0.02 and $11.88 \% \mathrm{C} 18: 2$ trans-10,cis-12, respectively (Pappritz et al., 2011a). Based on the analysis of the concentrates and silages, the total intake of 
Table 1. Effects of feeding experimental diets during the preceding lactation period on milking performance of the first 3 wk of the following lactation and on performance of calves until d 50 of age (values are least squares means $\pm \mathrm{SE}$ of 5 to 6 replications)

\begin{tabular}{|c|c|c|c|c|c|c|c|c|}
\hline \multirow[b]{2}{*}{ Item } & \multicolumn{3}{|c|}{ Experimental diet ${ }^{1}$} & \multicolumn{5}{|c|}{ Probability $^{2}$} \\
\hline & $\mathrm{CON}$ & CLA50 & CLA100 & Diet & Sex & $\begin{array}{l}\text { Diet } \times \\
\text { sex }\end{array}$ & $\begin{array}{l}\text { Depletion } \\
\text { time }^{3}\end{array}$ & $\begin{array}{l}\mathrm{BW} \\
\text { at d } 0\end{array}$ \\
\hline \multicolumn{9}{|l|}{ Cows } \\
\hline Gestation period (d) & $283 \pm 2$ & $286 \pm 2$ & $285 \pm 2$ & 0.394 & & & 0.196 & 0.009 \\
\hline Milk yield (kg/d ) & $32.0 \pm 2.6$ & $32.2 \pm 0.9$ & $30.6 \pm 1.1$ & 0.790 & & & 0.946 & \\
\hline FCM $(\mathrm{kg} / \mathrm{d})$ & $31.4 \pm 7.5$ & $34.5 \pm 4.6$ & $35.5 \pm 1.7$ & 0.848 & & & 0.836 & \\
\hline Lactose (\%) & $3.6 \pm 0.5$ & $3.7 \pm 0.5$ & $4.5 \pm 0.1$ & 0.182 & & & 0.595 & \\
\hline $\mathrm{SCC}\left(\log _{10}\right.$ cells $\left./ \mathrm{mL}\right)$ & $1.5 \pm 0.5$ & $2.3 \pm 0.5$ & $1.8 \pm 0.5$ & 0.090 & & & 0.986 & \\
\hline \multicolumn{9}{|l|}{ Calves } \\
\hline $\mathrm{BW}(\mathrm{d} 0, \mathrm{~kg})$ & $43.7 \pm 2.8$ & $45.5 \pm 2.3$ & $43.3 \pm 2.2$ & 0.827 & 0.036 & 0.336 & 0.197 & \\
\hline BW gain $(\mathrm{d} 8-50, \mathrm{~kg} / \mathrm{d})$ & $0.767 \pm 0.052$ & $0.734 \pm 0.043$ & $0.685 \pm 0.041$ & 0.469 & 0.727 & 0.895 & 0.088 & 0.772 \\
\hline
\end{tabular}

${ }^{1} \mathrm{CON}=$ control fat supplement; CLA50 and CLA100 = fat supplement containing conjugated linoleic acids (CLA) at 50 or $100 \mathrm{~g} / \mathrm{d}$, respectively. ${ }^{2}$ Significant values $(P \leq 0.05)$ and tendencies $(P<0.1)$ are shown in bold.

${ }^{3}$ Depletion time is the individual period elapsed between the day of terminating the feeding of the experimental diet in the preceding lactation period and the day of calving.

cis-9,trans-11 and trans-10,cis-12 CLA by CLA50 and CLA100 amounted to 4 and $8 \mathrm{~g} / \mathrm{d}$ each, respectively.

\section{Performance of Cows and Calves}

Performance of the cows (DMI, milk yield, BW) during the preceding lactation period, in which the cows were fed the experimental diets, are presented in detail in a related publication (Pappritz et al., 2011a). The BW of cows at time of depletion; that is, at the time of terminating feeding of the fat supplements for $182 \mathrm{~d}$ in the preceding lactation period, were $591 \pm 23 \mathrm{~kg}, 626 \pm$ $26 \mathrm{~kg}$, and $595 \pm 16 \mathrm{~kg}$ for CON, CLA50, and CLA100, respectively, and were not significantly influenced by treatment. Further data relevant for interpretation of the present study are cited in the discussion section.

When all cows were included, depletion times ranged from 190 to 262 d, and were 234, 228, and 228 d, respectively, on average when CON, CLA50, and CLA100 were considered separately.

The gestation period varied between 276 and 292 $\mathrm{d}$ and was not influenced by dietary treatment in the early gestation period (Table 1), whereas it increased significantly with the birth weight of calves (Figure 1A). Neither milk performance (milk yield, milk fat, protein, and lactose) nor SCC was significantly influenced by dietary treatment or depletion time (Table 1) during the first 3 wk after calving. The BW after calving were not different between groups and were $602 \pm 19 \mathrm{~kg}, 654 \pm$ $24 \mathrm{~kg}$, and $617 \pm 16 \mathrm{~kg}$, for CON, CLA50, and CLA100 cows, respectively. Further measurements of BW were not undertaken, and feed intake could not be recorded during the dry period or the 3 -wk period after calving.
A)

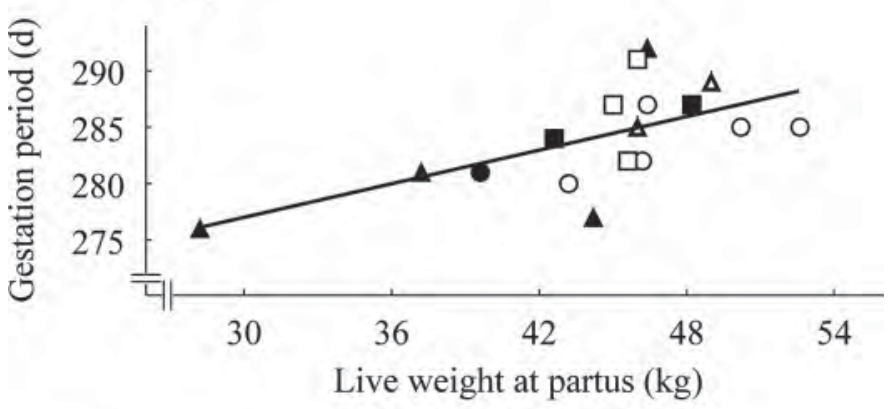

B)

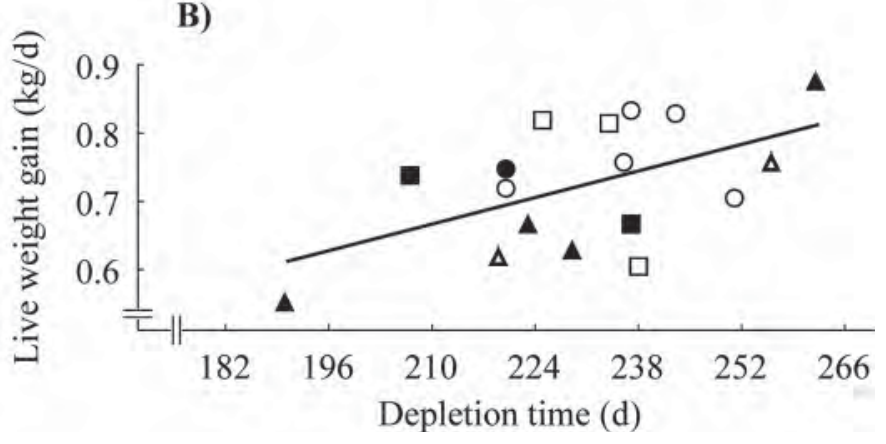

Figure 1. Relationship between (A) live weight (x-axis, $\mathrm{kg}$ ) and gestation length (y-axis, d): $\mathrm{y}=262(P<0.001)+0.5(P=0.007)$ $\mathrm{x}\left[\mathrm{R}^{2}=0.39\right.$; residual standard deviation $\left.(\mathrm{RSD})=4 \mathrm{~d}\right]$ and between (B) depletion time (x-axis, $\mathrm{d}$ ) and daily live weight gain of calves (d 8 to 50 of age $)(\mathrm{y}$-axis, $\mathrm{kg} / \mathrm{d}): \mathrm{y}=0.075(P=0.778)+0.003(P=0.025)$ $\mathrm{x}\left(\mathrm{R}^{2}=0.29 ; \mathrm{RSD}=0.08 \mathrm{~kg} / \mathrm{d}\right) . \mathrm{CON}=$ control fat supplement $(\mathrm{O}=$ male, $\bullet=$ female); CLA50 ( $\square=$ male, $\mathbf{\square}=$ female) and CLA100 ( $\Delta=$ male, $\mathbf{\Delta}=$ female) $=$ fat supplement containing conjugated linoleic acids (CLA) at 50 or $100 \mathrm{~g} / \mathrm{d}$, respectively. 
Birth weight of the calves was significantly higher for males than for females but was unaffected by CLA supplementation of the diets of their mothers during early lactation and by depletion time. Body weights of the calves were observed for a total of $50 \mathrm{~d}$ and BW gain during the milk replacer feeding period was not influenced by dietary treatment of their dams or by sex or birth weight, whereas depletion time tended to affect BW gain (Table 1). The linear regression of depletion time on daily $\mathrm{BW}$ gain suggested that the longer the depletion period, the greater the BW gain of the calves (Figure 1B).

\section{Hematology, Immune Function, and Plasma Metabolites}

Cows. Hematocrit decreased significantly from $37 \%$ on d 0 to $30 \%$ after $21 \mathrm{~d}$ in milk (Table 2) and was not affected by the fixed factors, diet and examination day, or by the co-variable, depletion time. Comparable significance relationships were found for total leukocytes $(-37 \%)$ and segmented neutrophils $(-56 \%)$ and a similar trend was observed for monocytes $(-67 \%)$, whereas eosinophils increased significantly at the same time $(+219 \%)$. Banded neutrophils and lymphocytes were not affected by day, diet, or their interactions. However, depletion time significantly affected the lymphocyte counts with a time-dependent decreasing effect (Table 2, Figure 2A).

The SI for the PBMC increased significantly by 77 and $56 \%$ after calving according to the MTT and AB assays, respectively. However, feeding of $50 \mathrm{~g} / \mathrm{d}$ of the CLA product caused a decrease in SI after $21 \mathrm{~d}$ in milk compared with groups CON and CLA100, which caused significant interactions between day and diet for the MTT assay.

With the exception of plasma albumin, all measured metabolites were significantly influenced by measurement day, whereas the other fixed factors remained without influence (Table 2). In particular, total bilirubin, glucose, and NEFA decreased from 7.9 to 2.15 $\mu \mathrm{mol} / \mathrm{L}$, from 6.52 to $3.23 \mathrm{mmol} / \mathrm{L}$, and from 944 to $469 \mu \mathrm{mol} / \mathrm{L}$, respectively, whereas cholesterol, BHBA, and total protein increased from 1.33 to $3.17 \mathrm{mmol} / \mathrm{L}$, from 0.45 to $1.06 \mathrm{mmol} / \mathrm{L}$, and from 59 to $70 \mathrm{~g} / \mathrm{L}$, respectively.

The apparently higher BHBA content in CLA100 $(1.69 \mathrm{mmol} / \mathrm{L})$ in the present experiment compared with the other groups 3 wk after calving was caused by one ketotic individual with BHBA and glucose contents of 5.26 and $1.79 \mathrm{mmol} / \mathrm{L}$, respectively, whereas other hematological and clinical-chemical parameters were in the normal range. This individual condition was not associated with a decreased SI, which amounted to 5.6 and 5.3, according to the MTT and AB assays, respectively, indicating that this ketotic condition did not compromise the PBMC in responding to the mitogen ConA.

Only depletion time affected the cholesterol level significantly and the positive regression coefficient suggested an increase with a longer depletion time (not shown). Nonesterified fatty acids were negatively related to SI, whereas BHBA showed the opposite effect. Approximately $56 \%$ of the variation of SI could be explained by the variation in NEFA and BHBA (Figure 2B).

Calves. In calves, hematocrit showed a trend to decrease when measured immediately after birth compared with d 1 (Table 3). White blood cell count and profile was not influenced by the fixed factors diet and examination day or by the co-variable depletion time. Only the eosinophils tended to increase from 0.02 on $\mathrm{d}$ 0 to 0.16 giga $\left(10^{9}\right.$ cells)/L at d 1 (Table 3$)$. The significant diet effect on SI according to the MTT assay was the result of the decrease measured for PBMC isolated from calves whose dams belonged to the CLA50 group, whereas SI was comparable for PBMC from calves whose mothers were treated with CON and CLA100 (Table 3). The AB assay failed to detect this effect. Plasma glucose increased significantly from 6.25 to 8.87 $\mathrm{mmol} / \mathrm{L}$ due to colostrum intake as did the protein content (54 vs. $61 \mathrm{~g} / \mathrm{L}$ ), whereas NEFA decreased significantly from 839 to $478 \mu \mathrm{Eq} / \mathrm{L}$ at the same time, and BHBA content (0.22 to $0.1 \mathrm{mmol} / \mathrm{L})$ showed a similar trend $(P=0.070)$.

\section{FA Profile of Erythrocyte Lipids}

Cows. Feeding of the different fat supplements until d 182 of the preceding lactation exerted no long-term effect on the fatty acid pattern of erythrocyte lipids of cows, either on the day of birth or after $21 \mathrm{~d}$ in the following lactation period (Table 4). The proportion of SFA decreased significantly from 33 to $29 \%$ from birth to d 21 in milk. In particular, C18:0 decreased significantly from 16 to $14 \%$ with a similar trend for C14:0, which decreased from 0.5 to $0.3 \%$. The mean proportion of the most abundant fatty acid, C18:1 cis9 , was approximately $49 \%$ and was not influenced by the considered fixed and co-variable effects. In contrast, the proportion of the sum of C18:1 trans fatty acids increased significantly from 0.9 to $1.2 \%$ from birth to d 21 in milk. Among the linoleic acids only C18:2 cis-9,cis-12 was significantly influenced by the day of measurement and increased significantly from 9.5 to $11.2 \%$ within $21 \mathrm{~d}$ in milk.

The mean proportion of approximately $0.32 \%$ of cis9,trans-11 CLA was not influenced by measurement 
DÄNICKE ET AL.

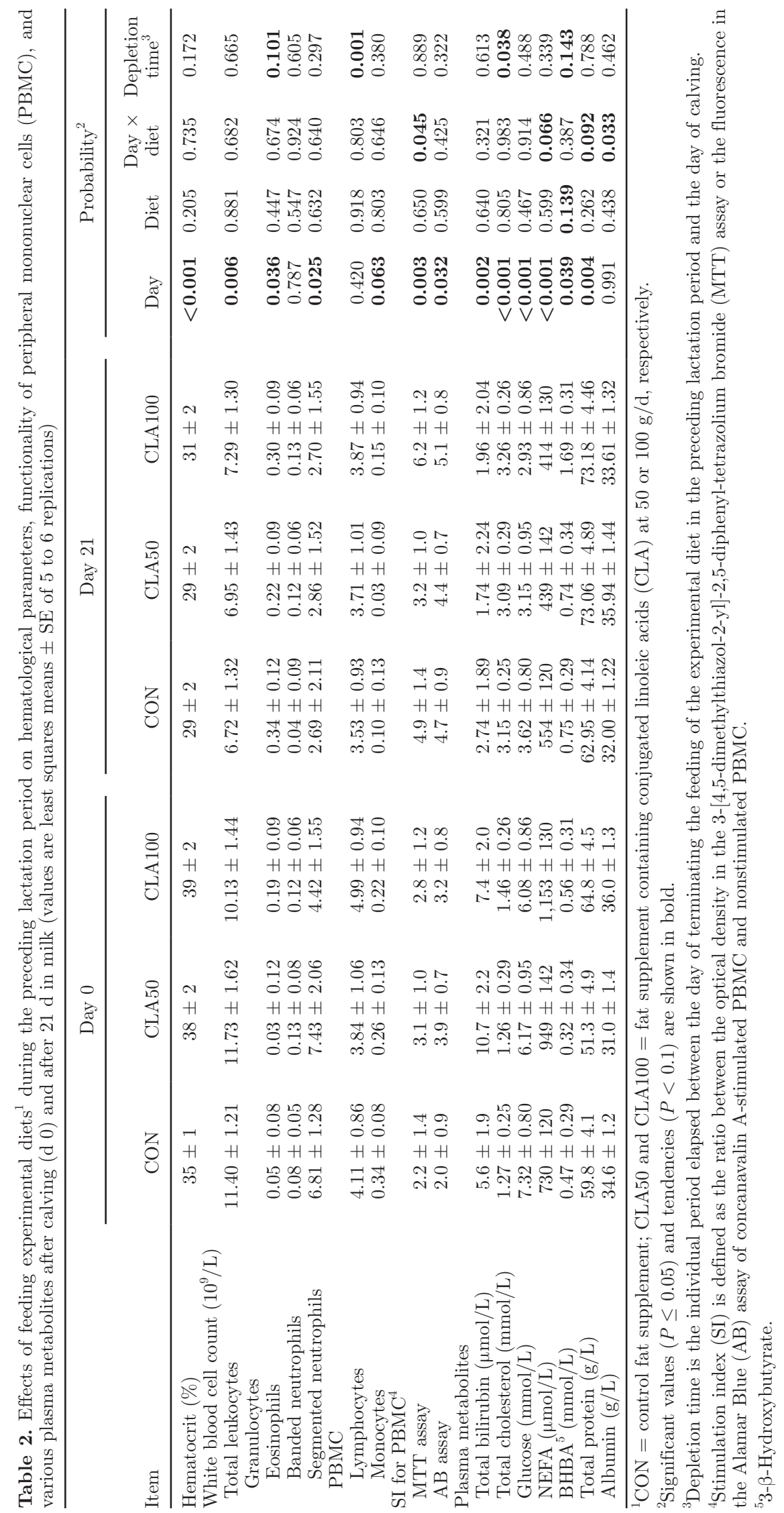



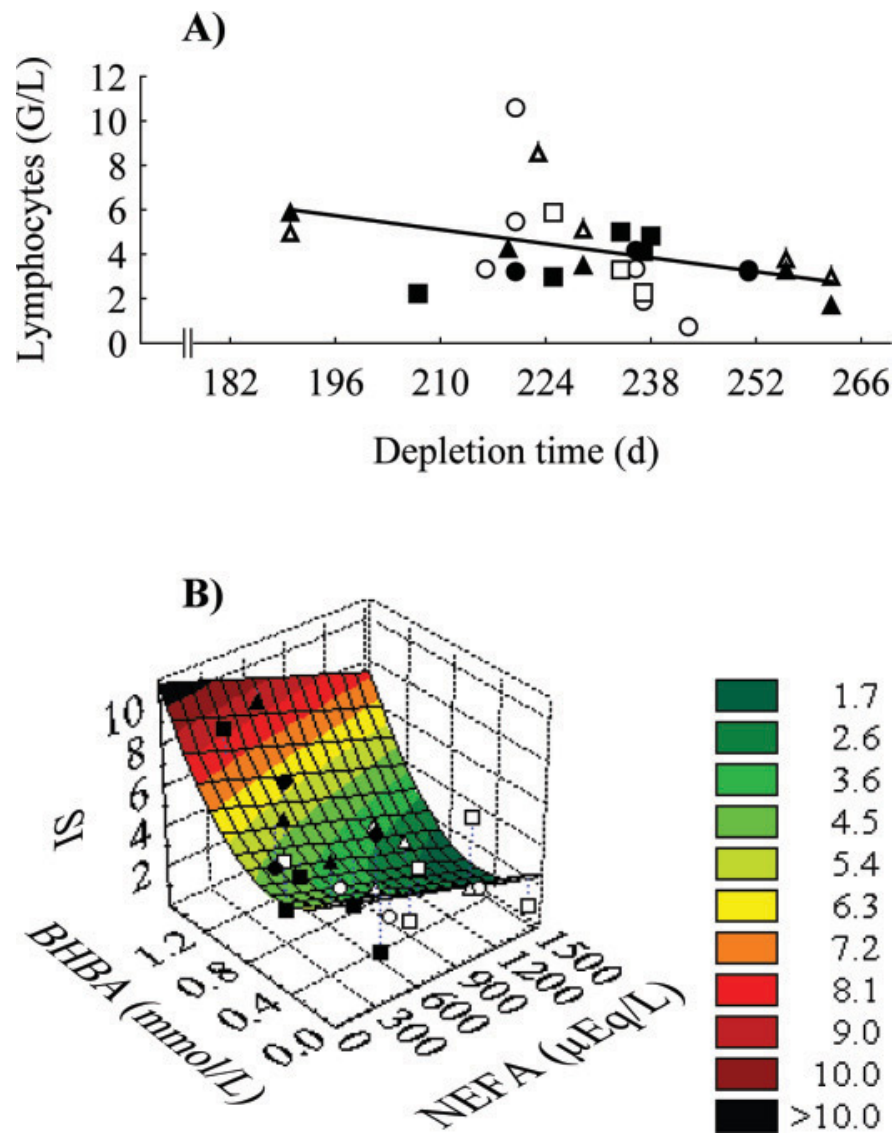

Figure 2. Relationship between (A) depletion time (x-axis, d) and lymphocyte counts of cows (y-axis, G/L): $\mathrm{y}=14.3(P=0.004)$ $0.04(P=0.034) \mathrm{x}\left[\mathrm{R}^{2}=0.16\right.$; residual standard deviation $(\mathrm{RSD})=1.9$ $\mathrm{G} / \mathrm{L}]$, and between (B) NEFA (x-axis, $\mu \mathrm{Eq} / \mathrm{L}$ ), 3- $\beta$-hydroxybutyrate (BHBA; y, mmol/L), and stimulation index (SI) according to the 3-[4,5-dimethylthiazol-2-yl]-2,5-diphenyl-tetrazolium bromide (MTT) assay of cows (z-axis): $\mathrm{z}=6.1(P=0.002)-0.002(P=0.043) \mathrm{x}-$ $6.7(P=0.073) \mathrm{y}+6.3(P=0.01) \mathrm{y}^{2}\left(\mathrm{R}^{2}=0.56, \mathrm{RSD}=1.7\right) . \mathrm{CON}=$ control fat supplement $(\bigcirc=\mathrm{d} 0, \boldsymbol{\bullet}=\mathrm{d} 21)$, CLA50 $(\square=\mathrm{d} 0, \boldsymbol{\square}=$ $\mathrm{d} 21)$ and $\operatorname{CLA} 100(\Delta=\mathrm{d} 0, \boldsymbol{\Delta}=\mathrm{d} 21)=$ fat supplement containing conjugated linoleic acids (CLA) at 50 or $100 \mathrm{~g} / \mathrm{d}$, respectively. Color version available in the online PDF.

day or by depletion time, whereas the trans-10, cis-12 CLA isomer was not detectable at all.

Calves. In contrast to the FA profile of erythrocyte lipids of cows, that of their calves was partly influenced by feeding the fat supplements during the early gestation period (Table 5). The proportion of C16:0 was significantly higher by 2 to $3 \%$ in erythrocyte lipids of calves born from cows of CLA100, whereas a measurement day effect was not detected. In contrast, C18:0 significantly increased after colostrum intake, and this effect seemed to be manifested at a higher level for the CLA100 calves, although it failed to reach significance. However, as both of these FA comprised the majority of SFA, this diet effect was also significant for the sum of all SFA.
The percentage of C16:1 decreased significantly from birth to $1 \mathrm{~d}$ later and was slightly lower by approximately $0.5 \%$ in calves from CLA100. The proportion of C18:1 cis-9 decreased significantly within the first day after birth from approximately 48 to $45 \%$. The sum of C18:1 trans-fatty acids increased significantly within $1 \mathrm{~d}$ after birth due to colostrum intake from 0.26 to $0.51 \%$. Calves from CLA100 had slightly more of these FA in their erythrocyte lipids than did calves of the CON group, and this effect occurred consistently both immediately after birth and $1 \mathrm{~d}$ later, at a higher level for the latter measurement day. Due to the high percentage of C18:1 cis-9 of the sum of all MUFA, the significance relationships for this group of FA were similar to those of $\mathrm{C} 18: 1$ cis-9 alone.

We observed a tendency for C18:2 n- 6 to be decreased due to colostrum intake. In contrast, the C18:2 trans-9,trans-12 was significantly lower at d 0 in calves whose mothers were previously fed the CLA100 diet, whereas similar levels were found after colostrum intake at $\mathrm{d} 1$ of age (significant interactions between day and diet). Moreover, the proportion of this FA increased with the length of the depletion period (Figure 3). This effect occurred at a slightly lower level in calves from CLA100. Of the CLA, only cis-9,trans-11 CLA could be detected, which was slightly higher in calves born from the CLA100 group compared with the CON group. When considered together, both n- 6 and n-3 FA were detected at slightly lower proportions in erythrocyte lipids of calves from CL100 compared with those of CON. This conclusion could be drawn when all PUFA were considered together. Moreover, slightly less longchain fatty acids $(>\mathrm{C} 16)$ were also detected for the CLA100 calves.

Cows and Calves. Although erythrocyte FA of the C16 family (C16:0, C16:1) were significantly higher in calves than in their dams (Figure 4), some of the C18 fatty acids were characterized by a significant decrease (C18:0, C18:1 trans fatty acids, C18:2 n-6, C18:3 n-3, C18:2 cis-9,trans-11). Other mother-calf differences in FA failed to reach significance.

\section{FA Profile of Milk Fat}

Most of the FA changed significantly from colostrum fat at birth to milk fat at $21 \mathrm{~d}$ in milk (Table 6). Among the SFA, the short-chain fatty acids C4:0, C6:0, $\mathrm{C} 8: 0$, and C10:0, as well as the medium- and long-chain fatty acids C17:0 and C18:0, were all characterized by a significant increase from colostrum to milk, whereas C14:0 and C16:0 decreased significantly over the same period. As the latter 2 fatty acids comprised the majority of all SFA, the sum of SFA decreased significantly from approximately 73 to $65 \%$. Additionally, C18:0 
DÄNICKE ET AL.

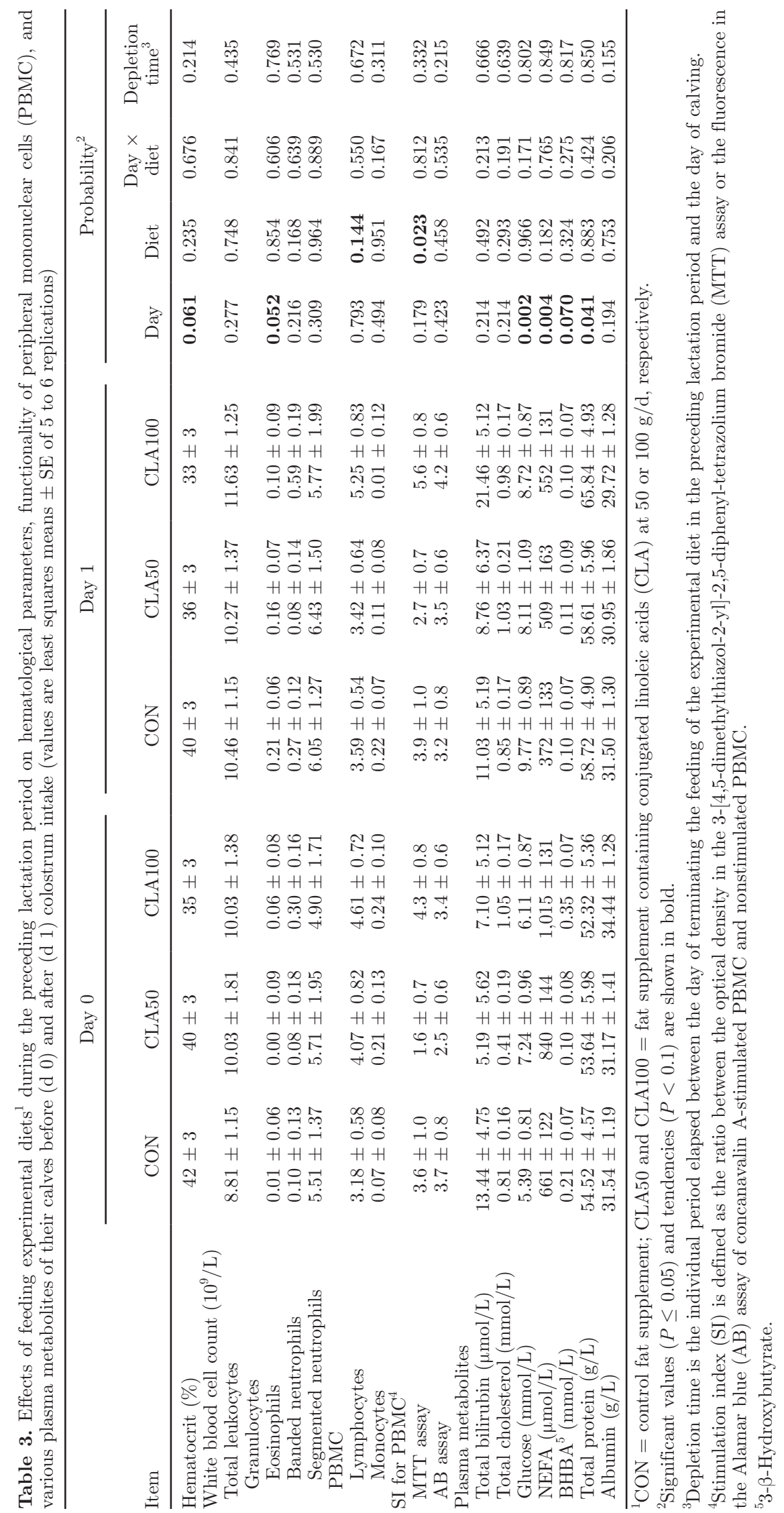


Table 4. Effects of feeding experimental diets ${ }^{1}$ during the preceding lactation period on the FA composition (\% of total FA methyl esters) of erythrocyte lipids after calving (d 0) and after $21 \mathrm{~d}$ in milk (values are least squares means $\pm \mathrm{SE}$ of 5 to 6 replications)

\begin{tabular}{|c|c|c|c|c|c|c|c|c|}
\hline \multirow[b]{2}{*}{ FA } & \multicolumn{2}{|c|}{ Day 0} & \multicolumn{2}{|c|}{ Day 21} & \multicolumn{4}{|c|}{ Probability $^{2}$} \\
\hline & $\mathrm{CON}$ & CLA100 & $\mathrm{CON}$ & CLA100 & Day & Diet & $\begin{array}{c}\text { Day } \times \\
\text { diet }\end{array}$ & $\begin{array}{c}\text { Depletion } \\
\text { time }^{3}\end{array}$ \\
\hline C12:0 & $0.05 \pm 0.08$ & $0.25 \pm 0.08$ & $0.03 \pm 0.09$ & $0.03 \pm 0.08$ & 0.192 & 0.239 & 0.264 & 0.280 \\
\hline C14:0 & $0.39 \pm 0.10$ & $0.59 \pm 0.11$ & $0.32 \pm 0.11$ & $0.25 \pm 0.11$ & 0.055 & 0.648 & 0.163 & 0.336 \\
\hline C14:1 & $0.10 \pm 0.03$ & $0.11 \pm 0.03$ & $0.06 \pm 0.04$ & $0.04 \pm 0.03$ & 0.140 & 0.899 & 0.690 & 0.226 \\
\hline C15:0 & $0.25 \pm 0.04$ & $0.31 \pm 0.04$ & $0.30 \pm 0.04$ & $0.26 \pm 0.04$ & 0.965 & 0.830 & 0.138 & 0.436 \\
\hline C18:0 & $15.64 \pm 0.95$ & $16.72 \pm 1.04$ & $14.79 \pm 1.02$ & $13.87 \pm 1.04$ & 0.025 & 0.951 & 0.175 & 0.396 \\
\hline C18:1 cis-9 & $48.82 \pm 1.29$ & $46.48 \pm 1.42$ & $48.38 \pm 1.45$ & $51.04 \pm 1.42$ & 0.156 & 0.917 & 0.093 & 0.554 \\
\hline $\mathrm{C} 18: 1$ trans $\mathrm{FA}$ & $0.73 \pm 0.12$ & $0.99 \pm 0.14$ & $1.22 \pm 0.14$ & $1.08 \pm 0.14$ & 0.033 & 0.692 & 0.123 & 0.797 \\
\hline C18:2 trans- 9, trans -12 & $0.16 \pm 0.02$ & $0.18 \pm 0.03$ & $0.17 \pm 0.03$ & $0.16 \pm 0.03$ & 0.818 & 0.875 & 0.619 & 0.637 \\
\hline C18:2n-6 & $10.44 \pm 0.89$ & $8.52 \pm 0.98$ & $11.19 \pm 0.98$ & $11.26 \pm 0.98$ & 0.043 & 0.441 & 0.211 & 0.765 \\
\hline C18:2 cis-9,trans-11 & $0.36 \pm 0.04$ & $0.32 \pm 0.04$ & $0.31 \pm 0.04$ & $0.30 \pm 0.04$ & 0.258 & 0.636 & 0.698 & 0.584 \\
\hline Other CLA & $0.01 \pm 0.01$ & $0.03 \pm 0.01$ & $0.00 \pm 0.01$ & $0.00 \pm 0.01$ & 0.103 & 0.357 & 0.370 & 0.650 \\
\hline n-3 FA & $0.96 \pm 0.19$ & $0.95 \pm 0.21$ & $0.83 \pm 0.21$ & $0.81 \pm 0.21$ & 0.419 & 0.956 & 0.991 & 0.724 \\
\hline $\mathrm{n}-6 \mathrm{FA}$ & $13.69 \pm 1.36$ & $11.29 \pm 1.49$ & $14.44 \pm 1.49$ & $14.75 \pm 1.49$ & 0.094 & 0.564 & 0.257 & 0.864 \\
\hline n-3 FA/n-6 FA & $0.07 \pm 0.01$ & $0.08 \pm 0.01$ & $0.06 \pm 0.01$ & $0.05 \pm 0.01$ & 0.050 & 0.701 & 0.244 & 0.942 \\
\hline $\mathrm{FA}<\mathrm{C} 16$ & $1.08 \pm 0.26$ & $1.63 \pm 0.29$ & $0.97 \pm 0.29$ & $0.83 \pm 0.29$ & 0.056 & 0.565 & 0.127 & 0.985 \\
\hline $\mathrm{FA}=\mathrm{C} 16$ & $13.97 \pm 1.64$ & $16.57 \pm 1.80$ & $14.35 \pm 1.76$ & $13.22 \pm 1.80$ & 0.231 & 0.745 & 0.142 & 0.885 \\
\hline $\mathrm{FA}>\mathrm{C} 16$ & $85.04 \pm 1.84$ & $81.89 \pm 2.02$ & $84.76 \pm 1.97$ & $86.00 \pm 2.02$ & 0.164 & 0.712 & 0.116 & 0.913 \\
\hline
\end{tabular}

${ }^{1} \mathrm{CON}=$ control fat supplement; CLA50 and CLA100 = fat supplement containing conjugated linoleic acids (CLA) at $50 \mathrm{gr} 100 \mathrm{~g} / \mathrm{d}$, respectively. ${ }^{2}$ Significant values $(P \leq 0.05)$ and tendencies $(P<0.1)$ are shown in bold.

${ }^{3}$ Depletion time is the individual period elapsed between the day of terminating the feeding of the experimental diet in the preceding lactation period and the day of calving.

seemed to be slightly higher, by approximately $1.5 \%$, in CLA100, but only when measured at $d \mathrm{0}$. The monounsaturated C14:1 decreased with the transition from colostrum to milk, whereas the cis and trans isomers of C18:1 increased during the same period. Because of the high proportion of C18:1 cis- 9 of all MUFA, the sum of MUFA also increased significantly from approximately 24 to $32 \%$. Among the linoleic acids, C18:2 cis-9, cis-12 and cis-9,trans-11 were significantly higher in milk than in colostrum, whereas only the cis-9,cis-12 isomer was slightly decreased in CLA100 compared with CON. In contrast, trans-10,cis-12 CLA could only be detected in traces; C18:3n-3 tended to be lower in milk than in colostrum and to be decreased in CLA100. The eicosanoids C20:4n-3 and C20:5n-3, as well as C22:6n-3, were characterized by a significant decrease related to time in lactation. Considering further sum parameters, all n-3 fatty acids were lower in milk than in colostrum, whereas n- 6 fatty acids remained uninfluenced. The C16 fatty acids decreased significantly from approximately 41 to $30 \%$, whereas $\mathrm{FA}>\mathrm{C} 16$ increased significantly from 31 to $44 \%$, and those $<\mathrm{C} 16$ remained at a level of approximately $28 \%$.
The NEFA level in plasma of the cows was correlated to the proportion of some FA of the milk fat. For example, approximately $45 \%$ of the variation of the SFA and MUFA could be explained by NEFA variation (Figure 5A and B). Whereas the SFA increased with NEFA, the opposite was observed for MUFA.

\section{DISCUSSION}

\section{General Considerations of CLA Effects on Calves and Cows}

Although approximately $75 \%$ of the weight increase of the bovine fetus is confined to the last 2 mo of gestation and the nutrient requirement of the developing fetus during the first months of gravidity is relatively low, nutrition might exert distinct effects on pre- and postnatal development during this sensitive phase (Funston et al., 2010). In the present study, the possible maternal stimulus originated from the diets of the dams and included a supply with CLA. As the cows were fed the experimental diets for $182 \mathrm{~d}$ after calving in the previous lactation, the direct dietary effects on 


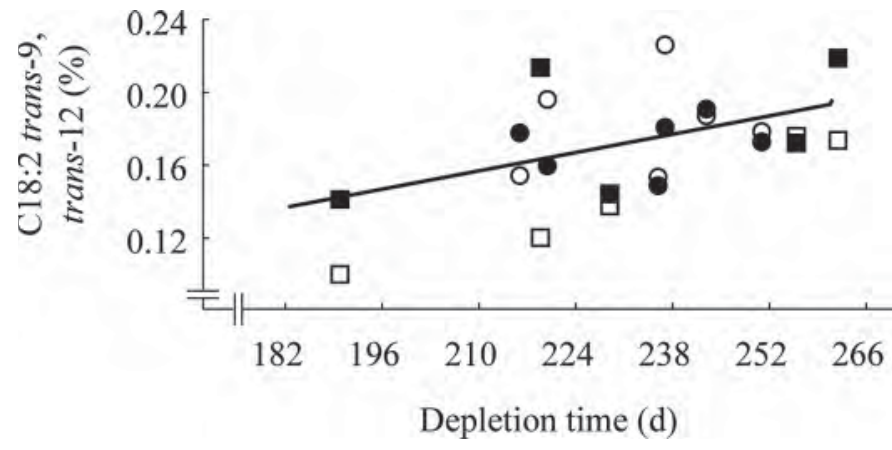

Figure 3. Relationship between depletion time (x-axis, d) and C18:2 trans-9,trans-12 proportion in erythrocyte lipids of calves (yaxis, \% of FA methyl esters). CON $=$ control fat supplement $(O=d 0$, $\boldsymbol{\bullet}=\mathrm{d} 21)$; CLA100 $(\square=\mathrm{d} 0, \boldsymbol{\square}=\mathrm{d} 21)=$ fat supplement containing conjugated linoleic acids (CLA) at $100 \mathrm{~g} / \mathrm{d}$.

the developing fetus occurred only during the last third of this period when the cows were in early stages of the subsequent gravidity. With regard to the present experiment, it should be noted that fetal exposure time to the experimental diets of their dams varied from 19 to 102 d. During this period, important events in fetal immune system development take place. The bovine fetal spleen develops around d 55 of gestation with reticulocytes being the predominant cell type and lymphoid cells appearing some days later. Red and white pulp structures of the spleen can be identified at $\mathrm{d} 80$, whereas lymphoid development of the thymus is detected at d 42 of gestation. Blood lymphocytes were found from d 45 in fetuses (Schultz et al., 1973).

In the present experiment, the functionality of the immune system of the newborn calves was tested after the dietary intervention of their mothers had been concluded 190 to 262 d earlier (i.e., the depletion time) by determining the stimulation ability of the PBMC isolated from unsuckled calves. Stimulation indices were unrelated to depletion or exposure time, which was similar for all treatment groups and cannot explain the significantly higher SI measured for the calves whose dams were fed the CLA100 diet instead of the CLA50 diet. As the SI determined for the CON and CLA100 groups were not significantly different, the lower SI for the CLA50 group has to be interpreted as a real decrease. This lower stimulation ability of the PBMC cannot be explained by the other data measured in the study.

Birth is an important event in the maturation of the immune system as the neonate is exposed to a variety of not-yet-experienced antigens and is supplied with co-

Table 5. Effects of feeding experimental diets ${ }^{1}$ during the preceding lactation period on the FA composition (\% of total FA methyl esters) of erythrocyte lipids of their calves before $(\mathrm{d} 0)$ and after $(\mathrm{d} 1)$ colostrum intake (values are least squares means $\pm \mathrm{SE}$ of 5 to 6 replications)

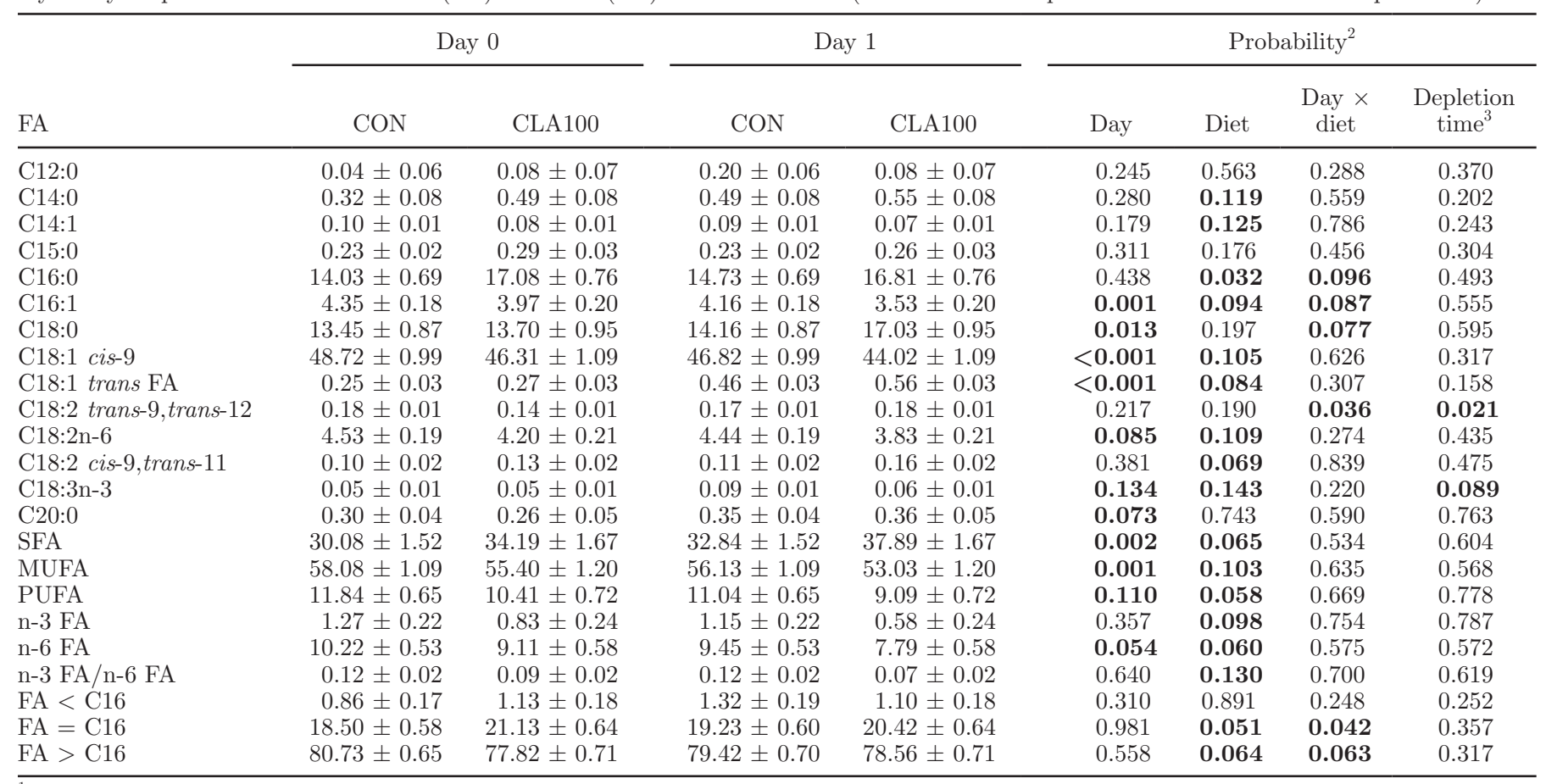

${ }^{1} \mathrm{CON}=$ control fat supplement; CLA50 and CLA100 = fat supplement containing conjugated linoleic acids (CLA) at $50 \mathrm{gr} 100 \mathrm{~g} / \mathrm{d}$, respectively. ${ }^{2}$ Significant values $(P \leq 0.05)$ and tendencies $(P<0.1)$ are shown in bold.

${ }^{3}$ Depletion time is the individual period elapsed between the day of terminating the feeding of the experimental diet in the preceding lactation period and the day of calving. 


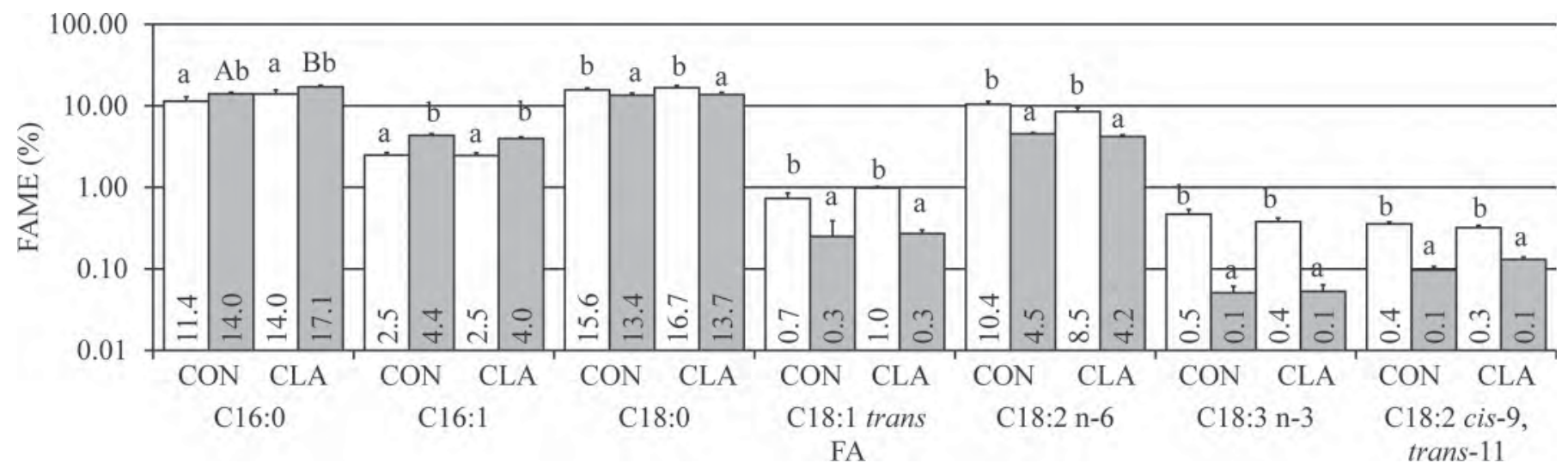

Figure 4. Fatty acid profiles of erythrocytes of cows (white bars) and their calves (gray bars) measured directly after partus (d 0) for CON $(\mathrm{n}=5)$ and CLA100 $(\mathrm{n}=6) . \mathrm{CON}=$ control fat supplement; CLA100 = fat supplement containing conjugated linoleic acids (CLA) at 100 $\mathrm{g} / \mathrm{d}$. Bars and half-whiskers represent mean values and standard errors; mean value differences between pairs of cows and calves within group were tested for significance using $t$-test for paired variables (indicate significant differences between mothers and calves are denoted by different lowercase letters), whereas mean value differences between cows or calves of CON and CLA groups were evaluated by $t$-test for independent variables (significant differences are denoted by different uppercase letters).

Table 6. Effects of feeding experimental diets ${ }^{1}$ during the preceding lactation period on the FA composition (\% of total FA methyl esters) of milk fat after calving (d 0) and after $21 \mathrm{~d}$ in milk (values are least squares means \pm SE of 5 to 6 replications)

\begin{tabular}{|c|c|c|c|c|c|c|c|c|}
\hline \multirow[b]{2}{*}{ FA } & \multicolumn{2}{|c|}{ Day 0} & \multicolumn{2}{|c|}{ Day 21} & \multicolumn{4}{|c|}{ Probability $^{2}$} \\
\hline & $\mathrm{CON}$ & CLA100 & $\mathrm{CON}$ & CLA100 & Day & Diet & $\begin{array}{c}\text { Day } \times \\
\text { diet }\end{array}$ & $\begin{array}{l}\text { Depletion } \\
\text { time }\end{array}$ \\
\hline $\mathrm{C} 4: 0$ & $2.71 \pm 0.19$ & $2.90 \pm 0.20$ & $3.86 \pm 0.21$ & $3.66 \pm 0.23$ & 0.003 & 0.974 & 0.438 & 0.037 \\
\hline C6:0 & $1.57 \pm 0.13$ & $1.72 \pm 0.15$ & $2.57 \pm 0.15$ & $2.67 \pm 0.17$ & $<0.001$ & 0.381 & 0.882 & 0.167 \\
\hline C8:0 & $0.78 \pm 0.09$ & $0.87 \pm 0.10$ & $1.35 \pm 0.10$ & $1.45 \pm 0.11$ & 0.001 & 0.345 & 0.976 & 0.587 \\
\hline C10:0 & $1.78 \pm 0.22$ & $1.86 \pm 0.24$ & $2.79 \pm 0.24$ & $3.10 \pm 0.27$ & 0.002 & 0.417 & 0.680 & 0.946 \\
\hline C14:1 & $1.36 \pm 0.12$ & $1.11 \pm 0.13$ & $0.77 \pm 0.13$ & $0.76 \pm 0.15$ & 0.003 & 0.448 & 0.281 & 0.605 \\
\hline C15:0 & $0.72 \pm 0.13$ & $0.72 \pm 0.15$ & $0.99 \pm 0.15$ & $1.00 \pm 0.17$ & 0.074 & 0.996 & 0.967 & 0.469 \\
\hline C16:0 & $38.87 \pm 1.00$ & $37.55 \pm 1.09$ & $27.65 \pm 1.12$ & $27.68 \pm 1.27$ & $<0.001$ & 0.563 & 0.585 & 0.552 \\
\hline C16:1 & $2.54 \pm 0.23$ & $2.57 \pm 0.26$ & $2.13 \pm 0.26$ & $2.16 \pm 0.30$ & 0.129 & 0.914 & 0.975 & 0.704 \\
\hline C17:0 & $0.47 \pm 0.03$ & $0.50 \pm 0.04$ & $0.64 \pm 0.04$ & $0.60 \pm 0.04$ & 0.005 & 0.883 & 0.340 & 0.454 \\
\hline C18:0 & $5.94 \pm 0.45$ & $7.51 \pm 0.50$ & $10.39 \pm 0.49$ & $10.40 \pm 0.55$ & $<0.001$ & 0.054 & 0.239 & 0.471 \\
\hline C18:1 cis-9 & $17.62 \pm 1.54$ & $18.10 \pm 1.68$ & $23.89 \pm 1.72$ & $23.36 \pm 1.94$ & 0.005 & 0.988 & 0.760 & 0.827 \\
\hline C18:3n-3 & $0.34 \pm 0.01$ & $0.33 \pm 0.01$ & $0.33 \pm 0.01$ & $0.28 \pm 0.02$ & 0.055 & 0.079 & 0.216 & 0.651 \\
\hline C20:0 & $0.12 \pm 0.02$ & $0.13 \pm 0.02$ & $0.15 \pm 0.02$ & $0.12 \pm 0.02$ & 0.615 & 0.621 & 0.306 & 0.306 \\
\hline$C 20: 4 n-3$ & $0.06 \pm 0.01$ & $0.06 \pm 0.01$ & $0.01 \pm 0.01$ & $0.01 \pm 0.01$ & $<0.001$ & 0.886 & 0.648 & 0.307 \\
\hline C20:5n-3 & $0.11 \pm 0.01$ & $0.10 \pm 0.01$ & $0.04 \pm 0.01$ & $0.05 \pm 0.01$ & $<0.001$ & 0.930 & 0.359 & 0.531 \\
\hline C22:6n-3 & $0.03 \pm 0.01$ & $0.02 \pm 0.01$ & $0.00 \pm 0.01$ & $0.00 \pm 0.01$ & 0.007 & 0.423 & 0.343 & 0.931 \\
\hline SFA & $72.84 \pm 1.47$ & $72.61 \pm 1.60$ & $64.38 \pm 1.65$ & $65.57 \pm 1.86$ & 0.001 & 0.792 & 0.661 & 0.891 \\
\hline MUFA & $23.83 \pm 1.42$ & $24.31 \pm 1.56$ & $32.40 \pm 1.60$ & $31.40 \pm 1.80$ & 0.001 & 0.885 & 0.628 & 0.861 \\
\hline PUFA & $3.34 \pm 0.13$ & $3.08 \pm 0.14$ & $3.23 \pm 0.14$ & $3.00 \pm 0.16$ & 0.511 & 0.140 & 0.911 & 0.774 \\
\hline n-3 FA & $0.80 \pm 0.05$ & $0.73 \pm 0.06$ & $0.56 \pm 0.06$ & $0.47 \pm 0.06$ & 0.001 & 0.256 & 0.876 & 0.809 \\
\hline $\mathrm{n}-6 \mathrm{FA}$ & $2.30 \pm 0.09$ & $2.16 \pm 0.10$ & $2.35 \pm 0.10$ & $2.12 \pm 0.12$ & 0.961 & 0.121 & 0.691 & 0.760 \\
\hline n-3 FA/n-6 FA & $0.35 \pm 0.02$ & $0.34 \pm 0.03$ & $0.24 \pm 0.03$ & $0.22 \pm 0.03$ & 0.001 & 0.564 & 0.926 & 0.721 \\
\hline $\mathrm{FA}<\mathrm{C} 16$ & $29.47 \pm 1.27$ & $28.39 \pm 1.39$ & $26.18 \pm 1.42$ & $27.39 \pm 1.61$ & 0.198 & 0.963 & 0.480 & 0.489 \\
\hline $\mathrm{FA}=\mathrm{C} 16$ & $41.51 \pm 1.16$ & $40.24 \pm 1.27$ & $29.88 \pm 1.30$ & $29.99 \pm 1.47$ & $<0.001$ & 0.651 & 0.627 & 0.567 \\
\hline $\mathrm{FA}>\mathrm{C} 16$ & $30.35 \pm 1.44$ & $32.46 \pm 1.58$ & $44.55 \pm 1.63$ & $43.29 \pm 1.84$ & $<0.001$ & 0.801 & 0.333 & 0.868 \\
\hline
\end{tabular}

${ }^{1} \mathrm{CON}=$ control fat supplement; CLA50 and CLA100 = fat supplement containing conjugated linoleic acids (CLA) at 50 or $100 \mathrm{~g} / \mathrm{d}$, respectively. ${ }^{2}$ Significant values $(P \leq 0.05)$ and tendencies $(P<0.1)$ are shown in bold.

${ }^{3}$ Depletion time is the individual period elapsed between the day of terminating the feeding of the experimental diet in the preceding lactation period and the day of calving. 

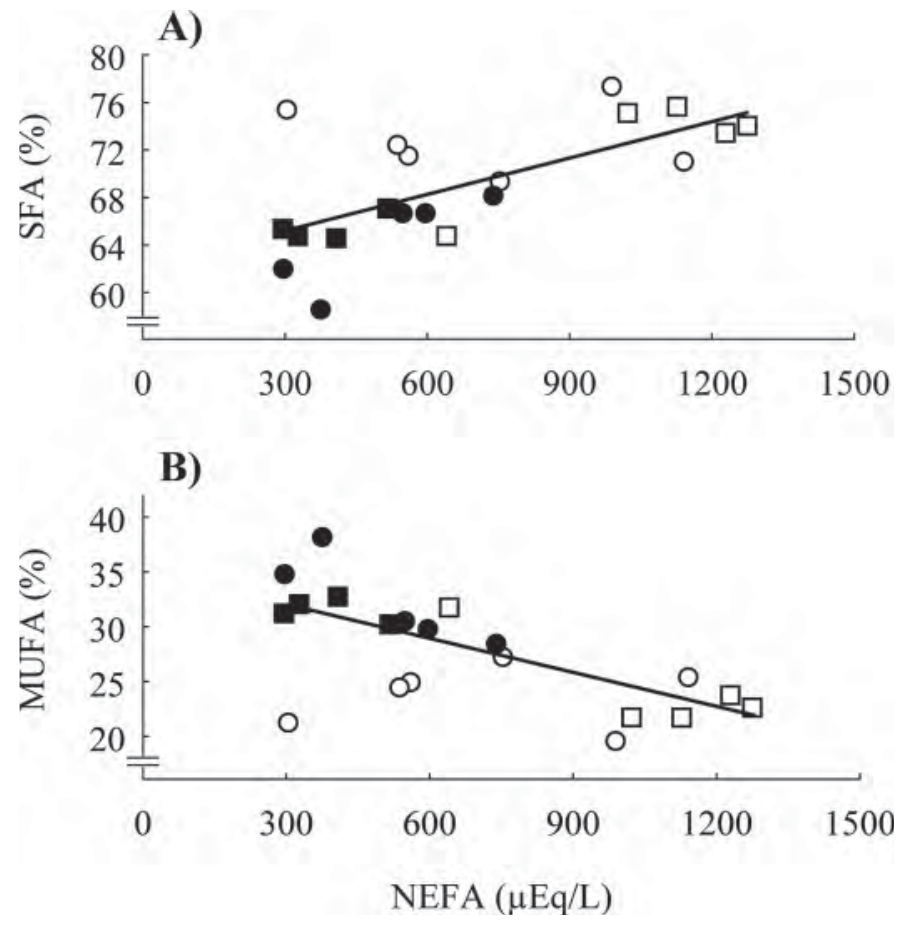

Figure 5. Relationship between (A) circulating NEFA in cows ( $\mathrm{x}$ axis, $\mu \mathrm{Eq} / \mathrm{L}$ ) and (A) sum of SFA (y-axis, $\%$ of FA methyl esters) in milk lipids: $\mathrm{y}=62.1(P<0.001)+0.01(P<0.001) \mathrm{x}\left[\mathrm{R}^{2}=0.45\right.$ residual standard deviation $(\mathrm{RSD})=3.9 \mu \mathrm{Eq} / \mathrm{L}]$, and $(\mathrm{B})$ sum of MUFA (y-axis, \% of FA methyl esters): y $=34.6(P<0.001)-0.01(P$ $<0.001) \times\left(\mathrm{R}^{2}=0.44, \mathrm{RSD}=3.9 \mu \mathrm{Eq} / \mathrm{L}\right) . \mathrm{CON}=$ control fat supplement $(O=\mathrm{d} 0, \bullet=\mathrm{d} 21)$; CLA100 $(\square=\mathrm{d} 0, \boldsymbol{\square}=\mathrm{d} 21)=$ fat supplement containing conjugated linoleic acids (CLA) at $100 \mathrm{~g} / \mathrm{d}$.

lostral antibodies, nutrients, and immune stimuli. Moreover, the gastrointestinal tract, as an important site of first-line defense, is colonized by bacteria (Calder et al., 2006). Although several plasma metabolites changed due to colostrum intake in the present experiment, the stimulation ability remained unaltered. Thus, colostral constituents were without consequences for the functionality of the PBMC within the considered period.

In addition to the decreased SI of PBMC of calves originating from the CLA50 group, the stimulation ability of PBMC isolated from the corresponding cows was also compromised. Although this effect became apparent only 3 wk postpartum, it raises questions about this unexpected CLA dose effect.

In an accompanying experiment with fistulated cows (Pappritz et al., 2011b), it was shown that the proportion of acetic acid in the rumen of the CLA50 group was significantly lower than that in the CON and CLA100 groups. Moreover, a significantly higher absolute and relative flow of the trans-10,cis-12 CLA at the duodenum indicated that rumen fermentation was influenced by CLA and that rumen protection (which was generally at a low level of 16 and $5 \%$ for CLA50 and CLA100, respectively) was affected by CLA dose in a nonlinear (quadratic) related manner. Although FA profiles of erythrocytes and milk of the CLA50 group were not measured in the present experiment, increased metabolic availability of the trans-10, cis-12 CLA for this group might be deduced based on the aforementioned increased flow of this isomer at the duodenum of cows fed the medium dose of $50 \mathrm{~g}$ of the used CLA preparation.

The activation of human PBMC was decreased in a dose-dependent manner when subjects were exposed to increasing doses of cis-9,trans-11 and trans-10, cis-12 CLA, which corresponded inversely to an increase in the lipids of PBMC (Tricon et al., 2004). The in vivo situation is even more complex when we consider that CLA act not only on immune cells, as discussed above, but also via a modification of other metabolites with the potential to influence immune function. Such metabolites also include other FA, which might be altered in response to CLA. Alterations in FA profiles might originate from the direct effects of CLA on FA synthesis or by influencing metabolism of body lipid stores, resulting in altered release of NEFA into the circulation. The absolute level of a mixture of FA representing a typical NEFA profile was shown to inhibit the mitogen-stimulated proliferation of bovine PBMC (Lacetera et al., 2004). In addition to the level of NEFA as such, its profile might also contribute to the mitogenic PBMC response as might be deduced from in vitro studies with a macrophage cell line comparatively investigating the effects of LPS, SFA, and UFA on cytokine expression (Shi et al., 2006). The FA C16:0 dosedependently stimulated expression of tumor necrosis factor- $\alpha$ mRNA in a similar fashion as LPS. Other SFA such as C14:0, C16:0, and C18:0 not only induced tumor necrosis factor- $\alpha$ but also IL6 mRNA, whereas the monounsaturated C18:1, one of the major FA of bovine lipids, failed to stimulate IL6. The stimulating effects of SFA were explained by the similarity to the recognition patterns of the inherent FA profile of the lipid A moiety of LPS. Assuming that the FA profile of the milk lipids mirrors the degree and the composition of the NEFA to some extent, it might be deduced that increasing NEFA levels are associated with increased proportions of SFA, whereas MUFA decrease at the same time (Figure 5). Thus, both higher absolute NEFA levels and presumably higher and lower proportions of SFA and MUFA, respectively, might be responsible for the apparent immune suppression in cows observed at the onset of lactation. Feeding of CLA in the preceding lactation did not affect these relationships. Considering these aspects together, it remains to be clarified if the rumen-related 
CLA effects influenced the lipid metabolism of both the calves in utero and the cows in a long-term persistent way.

\section{Comparative Aspects of FA Profiles of Erythrocyte Lipids of Cows and Calves}

The placental transfer of CLA was deduced by examining human maternal blood at wk 35 of gestation and of umbilical cord blood at birth for FA (Elias and Innis, 2001). Furthermore, negative correlations were found between the infant plasma cholesteryl ester CLA and triacylglycerol CLA content and the length of gestation and infant birth length (Elias and Innis, 2001). In addition, the cholesteryl ester CLA were inversely related to birth weight. In the present study, gestation length was not related to CLA feeding of the cows in the early gestational period. Rather, the length of gestation was only affected by birth weight, which in turn was not influenced by feeding regimens of the dams (Figure 1A).

Although the FA pattern of erythrocytes remained unaltered due to CLA feeding in the previous lactation period in cows, we observed some significant and tendency diet effects in calves. Most strikingly, the proportion of C16:0 was significantly increased in calves whose mothers were fed the CLA100 diet, whereas the proportions of $16: 1$ and C18:1 decreased in tendency at the same time.

Significant differences in the FA profiles of lipids in human maternal and cord blood lipids have been reported and were ascribed to differences in the selectivity of fatty acid binding proteins responsible for placental transfer of FA (Müller et al., 2007). Whether this selectivity also exists for bovine fatty acid binding proteins needs to be clarified. The $\alpha$-fetoprotein is another protein involved in fetal plasma lipid transport, transplacental fatty acid transfer, and lipid metabolism. An anionic ligand-binding site on bovine $\alpha$-fetoprotein was shown to be specific for bilirubin and essential unsaturated FA, whereas it was less specific for SFA. In the present experiment, no correlation was observed between the total bilirubin levels of cows and calves as measured directly after parturition $(\mathrm{r}=0.07)$. Although we observed a trend for an increased proportion of the cis-9,trans-11-CLA isomer in erythrocyte lipids of calves born from CLA100-treated cows, it is questionable if this increase arose from the supplementation of the cow's diet with the 2 CLA isomers because the trans-10,cis-12-CLA isomer (which is not, or is only to a minor extent, synthesized by the cow) was not detected in the erythrocyte lipids of cows or calves.

For some parameters measured in calves and cows, the depletion time exerted significant effects. These effects support the view that the diet or the diet change in the preceding lactation period influenced the metabolism of the calves and cows. These effects persisted significantly in calves where the daily BW gain after birth significantly increased with depletion time, whereas it remained uninfluenced by the feeding regimen of the dams (Figure 1B). In interpreting the effects of depletion time, we need to consider that this period was clearly related positively to calving interval and negatively to exposure time. Consequently, the effects ascribed to depletion time might be influenced by the other 2 processes. Thus, depletion time needs to be viewed as a compound indicator.

\section{Special Aspects of the Postpartal Cow}

An altered lipid metabolism, oxidative stress, and elevated circulating concentrations of NEFA are significant contributing factors to systemic inflammation in cattle. This plays an especially important role during the transit phase, where key host defense mechanisms undergo marked changes, leading to increased susceptibility to metabolic disorders and infectious diseases (Sordillo et al., 2009).

Although the diet effect in the present experiment did not reach significance, the cows released more NEFA at birth after CLA supplementation in the previous lactation period $(+30$ and $+58 \%$ in CLA 50 and CLA100, respectively, vs. CON), whereas no group differences were obvious after $21 \mathrm{~d}$ in milk, as indicated by the weak interaction effect between day and diet $(P=0.066)$. The NEFA decrease from birth to d 21 in milk was associated with a concomitant decrease in glucose and an increase in BHBA. The latter increased in tendency by $125 \%$ in CLA100 compared with CON 3 wk postpartum $(P=0.139)$, and was associated with an approximately $30 \%$ higher SI according to the MTT assay, whereas a decrease by the same proportion was observed in the CLA50 group. Together with a similarly directed increased SI at parturition of both CLA supplementation groups by 41 and $27 \%$ in CLA50 and CLA100, respectively, the significant interactions occurred. Both NEFA and BHBA were shown to influence immune cells in vitro. Thus, a more detailed regression analysis of the data seemed to be justified. A group-independent linear regression of the data revealed a weak positive effect of BHBA on SI determined by MTT assay (MTT-SI), whereas NEFA exerted a negative influence at the same time when both parameters were separately regressed on MTT-SI. Although the goodness of fit $\left(\mathrm{R}^{2}\right)$ reached only 0.13 and 0.20 , respectively, a combined multiple regression of NEFA (linear) and BHBA (linear and quadratic) on MTT-SI increased the $\mathrm{R}^{2}$ to 0.56 , which means that $44 \%$ of the MTT-SI variance could not be explained by NEFA and BHBA and corresponded to 
a residual standard deviation of the SI of 1.7 (Figure $2 \mathrm{~B})$. The multiple regression of NEFA and BHBA on SI suggests an increase in SI with decreasing NEFA levels and increasing BHBA concentrations $(<1.5 \mathrm{mmol} / \mathrm{L})$. Inclusion of further parameters indicative for negative energy balance such as glucose did not further enhance the variance explained.

According to this regression, BHBA concentrations $<1.5 \mathrm{mmol} / \mathrm{L}$ stimulated the ability of the PBMC to respond to the mitogen ConA. According to reported in vitro studies, the BHBA range around $1.5 \mathrm{mmol} / \mathrm{L}$ was identified as critical in some studies with regard to the function of bovine myeloid and erythroid progenitor cells (Hoeben et al., 1999) and to the respiratory burst activity of bovine neutrophils (Hoeben et al., 1997). In contrast, other studies found lower concentrations to be effective in depressing proliferation of PBMC (Targowski and Klucinski, 1983) and phagocytic activity of polymorphonuclear leukocytes (Kluciński et al., 1988). Moreover, even much higher BHBA concentrations (up to $6.25 \mathrm{mmol} / \mathrm{L}$ ) did not suppress ConA-stimulated PBMC proliferation (Franklin et al., 1991). However, for interpretation of the present data, the complex in vivo situation needs to be considered. The interferon production of ConA-stimulated PBMC isolated from cows with an experimentally induced ketosis (2.08 $\mathrm{mmol} / \mathrm{L}$ ) was significantly decreased (Filar et al., 1992). Moreover, a negative correlation between the phytohemagglutinin-stimulated interferon synthesis, and the blastogenic response of PBMC and circulating total ketone bodies was deduced. This correlation covered the range of $0.6,1.25$, and $4.25 \mathrm{mmol}$ of total ketone bodies/L, which corresponded to healthy cows and cows suffering from subclinical ketosis, and clinical ketosis, respectively (Kandefer-Szerszen et al., 1992). Lactating and dry cows (characterized by mean BHBA concentrations of 1.13 and $0.6 \mathrm{mmol} / \mathrm{L}$ ) had comparable ConA-stimulated PBMC proliferation rates, whereas a significant decrease was detected for ketotic cows having a mean systemic BHBA concentration of 2.03 $\mathrm{mmol} / \mathrm{L}$ (Sato et al., 1995). Although in the cited studies, high ketone body levels were also associated with high NEFA levels, this was not the case in the present experiment where the increase in BHBA concentrations was paralleled by lower NEFA levels (Figure 2B), which agrees with literature for the first weeks after parturition (e.g., Suriyasathaporn et al., 2000; Hachenberg et al., 2007).

\section{CONCLUSIONS}

Feeding of CLA-containing feed supplements to dairy cows in the preceding lactation period until 182 DIM exerted some long-term effects on the stimulation ability of PBMC of cows after the following parturition and of calves. Only feeding of $50 \mathrm{~g} / \mathrm{d}$ of the CLA supplement resulted in a significantly lower SI, whereas the higher dose of $100 \mathrm{~g} / \mathrm{d}$ was without effect. Whether or not these unexpected quadratic dose effects are due to differential CLA effects on rumen metabolism needs to be examined in further experiments. In addition, the FA profile of erythrocyte lipids was significantly altered in calves whose dams were fed the highest CLA dose. Taken collectively, the results suggest long-term effects of CLA feeding on cows and their offspring. To substantiate the current findings more conclusively, a higher number of replications per group is required, as well as continuous recording of nutrient and energy intake of cows and calves.

\section{ACKNOWLEDGMENTS}

The authors thank the Deutsche Forschungsgemeinschaft (DFG) for financial support (PAK 286/1, DA 558/5-1). Furthermore, the assistance of the co-workers of the Institute of Animal Nutrition and the Experimental Station of the Friedrich Loeffler Institute (FLI) in Braunschweig, Germany, in performing the experiment and analysis as well as the Institute of Nutrition of the Friedrich Schiller University (Jena, Germany) is gratefully acknowledged.

\section{REFERENCES}

Bauman, D. E., L. H. Baumgard, B. A. Corl, and J. M. Griinari 1999. Biosynthesis of conjugated linoleic acid in ruminants. Proc. Am. Soc. Anim. Sci. Accessed Mar. 24, 2012. http://www.asas. org/symposia/9899proc/0937.pdf.

Bauman, D. E., and J. M. Griinari. 2001. Regulation and nutritional manipulation of milk fat: low-fat milk syndrome. Livest. Prod. Sci. 70:15-29.

Bligh, E. G., and W. J. Dyer. 1959. A rapid method of total lipid extraction and purification. Can. J. Biochem. Physiol. 37:911-917.

Calder, P. C., S. Krauss-Etschmann, E. C. de Jong, C. Dupont, J. S. Frick, H. Frokiaer, J. Heinrich, H. Garn, S. Koletzko, G. Lack, G. Mattelio, H. Renz, P. T. Sangild, J. Schrezenmeir, T. M. Stulnig, T. Thymann, A. E. Wold, and B. Koletzko. 2006. Early nutrition and immunity - Progress and perspectives. Br. J. Nutr. 96:774790.

Dänicke, S., C. Keese, T. Goyarts, and S. Döll. 2011. Effects of deoxynivalenol (DON) and related compounds on bovine peripheral blood mononuclear cells (PBMC) in vitro and in vivo. Mycotox. Res. 27:49-55.

Elias, S. L., and S. M. Innis. 2001. Infant plasma trans, n-6, and n-3 fatty acids and conjugated linoleic acids are related to maternal plasma fatty acids, length of gestation, and birth weight and length. Am. J. Clin. Nutr. 73:807-814.

Filar, J., M. Kandefer-Szerszen, A. Szuster-Ciesielska, and W. Rzeski 1992. Effects of cold treatment and ketosis induced by starvation on interferon production in leukocytes of lactating cows. Dtsch. Tierarztl. Wochenschr. 99:210-213.

Folch, J., M. Lees, and G. H. S. Stanley. 1956. A simple method for the isolation and purification of total lipids from animal tissues. J. Biol. Chem. 226:497-509. 
Franklin, S. T., J. W. Young, and B. J. Nonnecke. 1991. Effects of ketones, acetate, butyrate, and glucose on bovine lymphocyte proliferation. J. Dairy Sci. 74:2507-2514.

Funston, R. N., D. M. Larson, and K. A. Vonnahme. 2010. Effects of maternal nutrition on conceptus growth and offspring performance: Implications for beef cattle production. J. Anim. Sci. 88:E205-E215.

GfE. 2001. Ausschuss für Bedarfsnormen der Gesellschaft für Ernährungsphysiologie: Empfehlungen zur Energie- und Nährstoffversorgung der Milchkühe und Aufzuchtrinder. DLG-Verlag, Frankfurt (Main), Germany.

Hachenberg, S., C. Weinkauf, S. Hiss, and H. Sauerwein. 2007. Evaluation of classification modes potentially suitable to identify metabolic stress in healthy dairy cows during the peripartal period. J. Anim. Sci. 85:1923-1932.

Hoeben, D., C. Burvenich, A. M. Massart-Leen, M. Lenjou, G. Nijs, B. D. Van, and J. F. Beckers. 1999. In vitro effect of ketone bodies, glucocorticosteroids and bovine pregnancy-associated glycoprotein on cultures of bone marrow progenitor cells of cows and calves. Vet. Immunol. Immunopathol. 68:229-240.

Hoeben, D., R. Heyneman, and C. Burvenich. 1997. Elevated levels of beta-hydroxybutyric acid in periparturient cows and in vitro effect on respiratory burst activity of bovine neutrophils. Vet. Immunol. Immunopathol. 58:165-170.

Jaudszus, A., P. Moeckel, E. Hamelmann, and G. Jahreis. 2010. Trans10,cis-12-CLA-caused lipodystrophy is associated with profound changes of fatty acid profiles of liver, white adipose tissue and erythrocytes in mice: Possible link to tissue-specific alterations of fatty acid desaturation. Ann. Nutr. Metab. 57:103-111.

Kandefer-Szerszen, M., J. Filar, A. Szuster-Ciesielska, and W. Rzeski. 1992. Suppression of interferon response of bovine leukocytes during clinical and subclinical ketosis in lactating cows. Dtsch. Tierarztl. Wochenschr. 99:440-443.

Kluciński, W., A. Degorski, E. Miernik-Degorska, S. Targowski, and A. Winnicka. 1988. Effect of ketone bodies on the phagocytic activity of bovine milk macrophages and polymorphonuclear leukocytes. Zentralbl. Veterinarmed. A 35:632-639.

Kraft, W., and U. M. Dürr. 2005. Klinische Labordiagnostik in der Tiermedizin. 6. Auflage, Schattauer, Stuttgart, Germany.

Lacetera, N., D. Scalia, O. Franci, U. Bernabucci, B. Ronchi, and A. Nardone. 2004. Short communication: Effects of nonesterified fatty acids on lymphocyte function in dairy heifers. J. Dairy Sci. 87:1012-1014.

Mir, P. S., T. A. McAllister, S. Scott, J. Aalhus, V. Baron, D. McCartney, E. Charmley, L. Goonewardene, J. Basarab, E. Okine, R. J. Weselake, and Z. Mir. 2004. Conjugated linoleic acid-enriched beef production. Am. J. Clin. Nutr. 79:1207S-1211S.
Müller, A., U. Keller, G. Seliger, C. Barthel, H. Steinhart, and K. Eder. 2007. Concentrations of conjugated linoleic acids in neonatal blood in relationship to those in maternal blood. Prostaglandins Leukot. Essent. Fatty Acids 76:213-219.

Naumann, C., and R. Bassler. 1993. Die Chemische Untersuchung von Futtermitteln. VDLUFA-Verlag, Darmstadt, Germany.

Pappritz, J., U. Meyer, R. Kramer, E. M. Weber, G. Jahreis, J. Rehage, G. Flachowsky, and S. Dänicke. 2011a. Effects of long-term supplementation of dairy cow diets with rumen-protected conjugated linoleic acids (CLA) on performance, metabolic parameters and fatty acid profile in milk fat. Arch. Anim. Nutr. 65:89-107.

Pappritz, J., U. Meyer, P. Lebzien, G. Flachowsky, and S. Dänicke. 2011b. Effects of supplementation of dairy cow rations with rumen-protected conjugated linoleic acids (CLA) on rumen metabolism. Eur. J. Lipid Sci. Technol. 113:1443-1455.

Renner, L., A. Schwabe, S. Döll, M. Höltershinken, and S. Dänicke. 2011. Effect of rare earth elements on beef cattle growth performance, blood clinical chemical parameters and mitogen stimulated proliferation of bovine peripheral blood mononuclear cells in vitro and ex vivo. Toxicol. Lett. 201:277-284.

Sato, S., T. Suzuki, and K. Okada. 1995. Suppression of mitogenic response of bovine peripheral blood lymphocytes by ketone bodies. J. Vet. Med. Sci. 57:183-185.

Schultz, R. D., H. W. Dunne, and C. E. Heist. 1973. Ontogeny of the bovine immune response. Infect. Immun. 7:981-991.

Selberg, K. T., A. C. Lowe, C. R. Staples, N. D. Luchini, and L. Badinga. 2004. Production and metabolic responses of periparturient Holstein cows to dietary conjugated linoleic acid and trans-octadecenoic acids. J. Dairy Sci. 87:158-168.

Shi, H., M. V. Kokoeva, K. Inouye, I. Tzameli, H. Yin, and J. S. Flier. 2006. TLR4 links innate immunity and fatty acid-induced insulin resistance. J. Clin. Invest. 116:3015-3025.

Sordillo, L. M., G. A. Contreras, and S. L. Aitken. 2009. Metabolic factors affecting the inflammatory response of periparturient dairy cows. Anim. Health Res. Rev. 10:53-63.

Suriyasathaporn, W.. C. Heuer, E. N. Noordhuizen-Stassen, and Y. H. Schukken. 2000. Hyperketonemia and the impairment of udder defense: A review. Vet. Res. 31:397-412.

Targowski, S. P., and W. Klucinski. 1983. Reduction in mitogenic response of bovine lymphocytes by ketone bodies. Am. J. Vet. Res. 44:828-830.

Tricon, S., G. C. Burdge, S. Kew, T. Banerjee, J. J. Russell, R. F. Grimble, C. M. Williams, P. C. Calder, and P. Yaqoob. 2004. Effects of cis-9,trans-11 and trans-10,cis-12 conjugated linoleic acid on immune cell function in healthy humans. Am. J. Clin. Nutr. $80: 1626-1633$. 